\title{
Communicating a safety-critical limitation of an infant-carrying product: The effect of product design and warning salience
}

\author{
J. Paul Frantz and James M. Miller \\ Department of Industrial and Operations Engineering, University of Michigan, Ann Arbor, MI 48109, USA
}

(Received February 15, 1992; accepted in revised form August 10, 1992)

\begin{abstract}
A field experiment was conducted to determine how the features of a product and the salience of its warnings affect potential purchasers' perceptions of a safety-critical product attribute. The experimental product was an infant carrier, which represents a class of products known to be inappropriately used as infant car seats. Sixty-two subjects were asked to examine and select an infant car seat/carrier product from a group of four infant-carrying products. Dependent measures included the subjects' knowledge that the experimental product was not designed to protect an infant in an auto accident and their attention to various warnings. Removing a potentially confusing product feature did not significantly reduce the proportion of subjects who mistakenly thought the product was designed for use as a car seat. However, collectively, the features of the product prompted more than a third of the subjects to incorrectly assess the safety-critical limitations of the product. Increasing the warning's salience significantly increased the proportion of subjects who noticed and read it, but only in the most conspicuous condition was there an increase in the proportion of subjects who correctly recognized the product's limitations.
\end{abstract}

\section{Relevance to industry}

Accidents and injuries associated with the use of products in unintended but reasonably foreseeable ways is a major industrial concern. This research addresses the role of product design and on-product warnings in preventing unintended, unsafe uses of consumer products. This study is particularly applicable to producers of consumer products concerned with conveying safety-critical messages at the point-of-purchase.

\section{Keywords}

Product safety; warnings; affordances; product design; infant carriers.

\section{Introduction}

Easily perceivable features of a product can provide users and potential users with a vast amount of non-verbal information from which they can make judgments about a product's structural composition, its method of operation, its

\footnotetext{
Correspondence to: J.P. Frantz, Department of Industrial and Operations Engineering, University of Michigan, Ann Arbor, MI 48109, USA.
}

basic functional and structural limitations, and its assembly or operational procedures (cf. Baggett and Ehrenfeucht, 1988; MacGregor, 1989; Norman, 1988; Rhoades, Frantz and Miller, 1990; Rhoades and Miller, 1992). For many consumer products, features such as knobs, dials, textures, shapes, and structural composition (e.g., glass, plastic, wood, etc.) can suggest, invite, or prohibit certain behaviors. Gibson (1977) and Norman (1988) referred to such features as 'affordances'. Gibson (1977) identified a number of generic categories of object affordances including 'sup- 
port', 'walk-on-able', 'sit-on-able', 'grasp-able', 'climb-on-able', and 'bump-into-able'. In a more applied context, Norman noted that affordances are those properties of objects, both perceived and actual, that suggest or imply how the object can be used. Essentially, product affordances allow people to draw upon previously learned skills, rules, and problem-solving strategies to interact with a novel product, as opposed to relying on external sources of information such as written instructions or warnings.

From an accident prevention standpoint, product features that provide strong cues about the use of a product are advantageous provided they do not promote or instigate inappropriate and unsafe usage of the product. While the features of a product are commonly considered when evaluating the usability of a product, the effect of various product features (i.e., affordances) is typically not evaluated in a systematic fashion with respect to product safety concerns. In fact, little research has addressed the effect of product features on consumers' / users' misperceptions of intended uses of a product. To investigate this product safety concern in a formal manner, a field experiment was conducted to determine how potential purchasers' perceptions of a safety-critical product attribute were affected by the features of a product and the conspicuity of its warnings.

\section{Description of product category}

The type of product involved in this study was an infant carrier. Infant carriers are designed to hold an infant during activities such as feeding, napping, and shopping. However, they are not designed to restrain or protect an infant in an automobile and are NOT designed to protect an infant in the event of an automobile accident. There are, however, two other types of products that are designed for this purpose: (1) infant car seat/carrier combinations which function as infant carriers but are also intended for use in automobiles, and (2) infant car seats (also known as child safety seats or child restraints) which are designed exclusively for restraining and protecting a child in an automobile. The latter two types of products have been designed to meet or exceed Federal Motor Vehicle Safety Standard 213
(U.S. DOT, 1981). The potential safety concern is that consumers may unknowingly purchase and use infant carriers as infant car seat / carrier combinations and subsequently have an automobile accident in which an infant is injured or killed due to the lack of protection provided by the infant carrier. This potential safety concern has been discussed in a variety of child passenger safety publications (Gillis and Fice, 1986; Jones, 1988; National Child Passenger Safety Association, 1985).

As opposed to examining the reasons and potential solutions for intentional misuse of infant carriers as car seats, this study focused on the problem of consumers unintentionally misusing infant carriers as car seats as a result of mistakenly believing the infant carrier to be an infant car seat/carrier combination. This confusion may arise for two reasons. First, consumers may not be aware that different categories of such infant products exist. That is, a consumer may assume that infant carriers and infant car seat/carrier combinations are one and the same. Second, consumers may be confused as to which product belongs in which category. Correctly identifying an infant carrier can be difficult because they often do not have obvious properties that distinguish them from car seat/carrier combinations. Generally speaking, products from both categories have straps for restraining the infant, a handle for carrying the product, a common shape, and a plastic shell construction. Readily observable features such as product weight, structural rigidity, shoulder strap design, in-store display characteristics, and price do not necessarily identify a particular product as a member of one of the two categories. Even retail sales personnel can provide incorrect information regarding the limitations of infant carriers. In fact, the only reliable distinction between infant carriers and infant car seat/carrier combinations is that the car seat/carriers will be accompanied by a statement indicating that the product has passed the requirements of FMVSS 213. The potential confusion between infant carriers and car seats was noted in a 1986 consumer guide to buying children's products: 'CAUTION: Some indoor baby seats look remarkably similar to infant safety seats. These are not crashworthy and should never be used as car safety seats' (Gillis and Fice, 1986). 


\section{Research objectives}

Using a particular infant carrier as an experimental product, the specific objectives of this research were to: (1) Determine the likelihood that potential purchasers would mistakenly perceive the subject carrier to be suitable for use as a car seat, (2) Determine the extent to which a particular product feature might prompt purchasers to mistakenly perceive the carrier to be suitable for use as a car seat, and (3) Determine the extent to which increasing the conspicuity of on-product warnings might reduce the propensity for consumers to incorrectly perceive the product to be suitable for use as a car seat.

\section{Method}

\section{Subjects}

Sixty-two subjects participated in the study. Fifteen subjects were assigned to each of three conditions and 17 subjects to a fourth condition (two extra subjects were interviewed in the fourth condition because there was some concern that difficulties with the audio/video transmission would result in missed portions of two interviews). Subjects were solicited from those attending or hosting one of the seven garage sales adjacent to which our experimental set-up was positioned for data collection. Approximately $90 \%$ of the people approached agreed to participate in the study. Generally speaking, after one interview was completed, the closest available person was approached and asked to participate. Subjects received $\$ 5$ for their participation. Random assignment of subjects to conditions was not possible due to the inability to inconspicuously change from one condition to another at any given time.

The age of the subjects ranged from 16 to 76 with a mean of 37.4 years. There were 46 females $(74 \%)$ and 16 males $(26 \%)$. Twenty-three percent $(23 \%)$ of the subjects had less than a high school education, $35 \%$ had completed high school, and $42 \%$ had at least some college education. Seventy-six percent $(76 \%)$ of the subjects had used an infant car seat at least once and $60 \%$ had either purchased or helped to purchase an infant car seat or carrier.

\section{Experimental setting and product display}

Four infant carrying products were displayed on a table in the vicinity of a garage sale. Figure 1 shows an example display. Two of the products were infant car seat/carriers which met the requirements of FMVSS 213 and the other two products were infant carriers only (i.e., not designed to protect an infant in the event of an automobile accident). The products were displayed with their point-of-purchase advertising information but without their shipping cartons. Price tags reflecting typical consumer prices were placed in the upper right-hand corner of each product.

The display was erected and data collected at seven different garage sale locations in middle and lower-middle income neighborhoods in a midwestern community of approximately 25,000 residents. Data collection occurred within a twoweek period in the summer of 1991 . To be selected as a data collection site, a garage sale location needed to have sufficient space for the display table and video recording equipment without endangering the subjects and without being too close to the garage sale merchandise (to prevent shoppers from overhearing the exchange between subject and experimenter).

A video camera recorded the subjects during their examination of the product and subsequent interview. The video camera and microphone were not concealed from the subjects in any way.

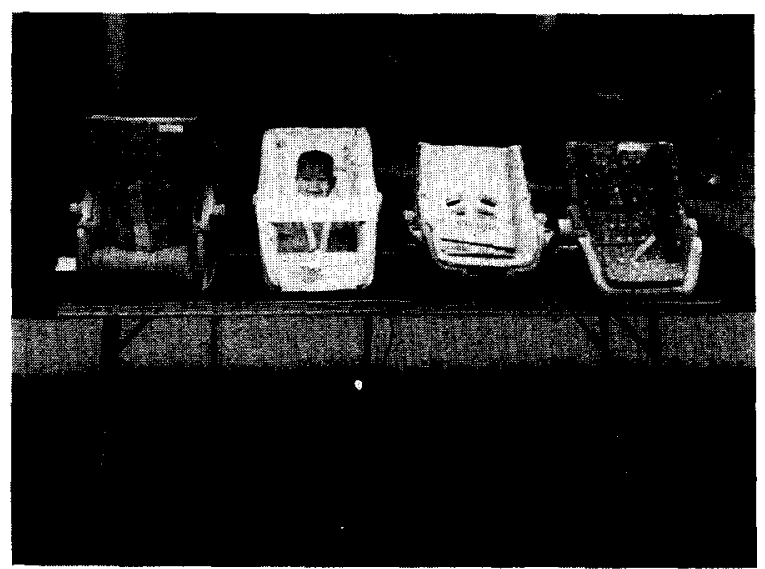

Fig. 1. Product display erected for data collection at one of the seven garage sale locations. 
The experimenter interviewed the subjects while another person controlled the video camera and recorded subject responses.

\section{Overview of experimental protocol}

Subjects were approached and asked if they would be willing to participate in a study to determine people's preferences for different infant products. Once a person agreed to participate, the experimenter instructed the subject as follows:

Imagine that you are shopping for an infant car seat that can also be used to carry an infant when walking from place to place. When you arrive at the store, this is the selection of products from which to choose. What $\mathbf{I}$ would like for you to do is select the one that you would purchase. Please take your time to inspect and handle the products just as you would if you were actually buying one of them. Keep in mind that I'm not asking you which one you like the most or which one you think is the most attractive, I'm asking you which one you would buy with your money. Let me know when you have made your decision.

The purpose of this introductory task was to allow the subjects to become familiar with the products. After subjects selected a product, they were asked if they noticed that the experimental product had a pouch in the back for carrying small baby supplies (see figure 2). For those subjects who did not notice the pouch, the interviewer picked up the product and held it so that the subject could look at the pouch. This was done to insure that each subject was at least exposed to an embossed warning on the back of the product which appeared directly above the pouch. This allowed for some measure of incidental attention to the warning on the back of the product.

Next, subjects were asked to concentrate on the experimental product and express their agreement or disagreement with several statements regarding the intended use of the product. For example, subjects were asked to indicate their agreement or disagreement with the statement: 'This product is designed for holding a baby while

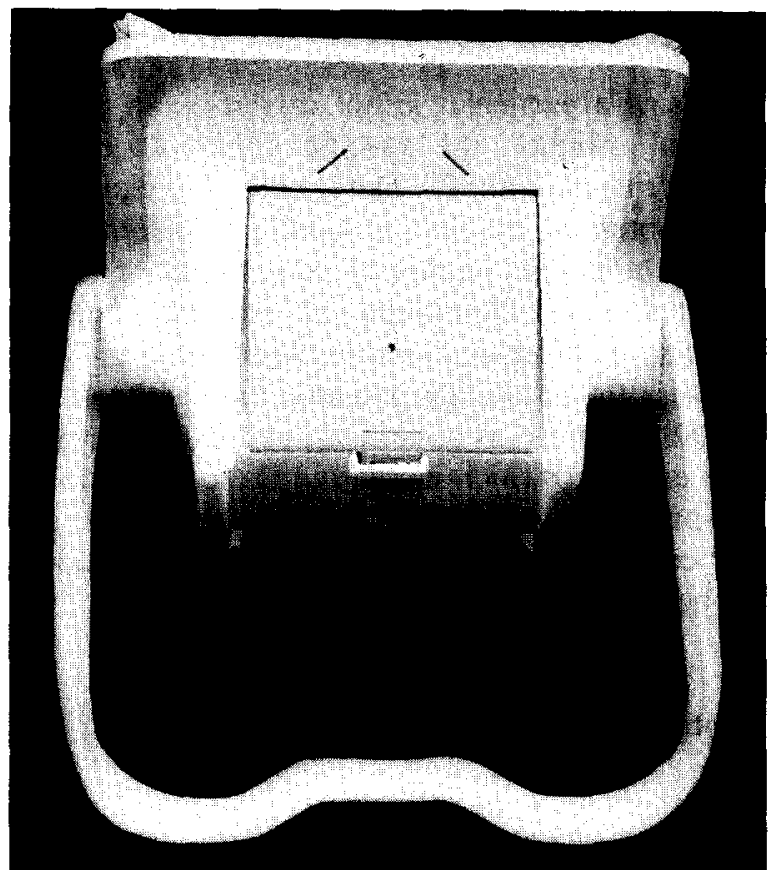

Fig. 2. Pouch in the back of the experimental infant carrier white-on-white embossed warning located above pouch.

it is riding in a car'. If subjects agreed with this statement, they were also asked to indicate their agreement or disagreement with the statement: 'This product is designed to protect a baby in the event of a car accident'.

Subjects were then asked if they noticed any warnings or cautions on the product and, if so, what the warnings said and where they were located. Next, subjects were asked to find those warnings or cautions which they had not previously noticed. Finally, after all of the key data were obtained, subjects were asked to express their opinion regarding the noticeability of each warning and provide recommendations for changes to the warnings or the product itself that would make it less likely for people to think that the subject infant carrier was a car seat.

\section{Experimental conditions and research hypotheses}

The experimental infant carrier was displayed in one of four conditions (see figure 3 ).

Condition 1 - Control condition (low warning salience / high affordance for use as a car seat). In this condition, the subject infant carrier was 
presented as it is currently sold to consumers. No alterations were made to the product or its warnings other than the addition of a price tag in the upper right-hand corner of the product. The manufacturer's point-of-purchase advertising, which was a cardboard insert in the shape and likeness of a baby, was strapped into the carrier as provided by the manufacturer.

Two warnings appeared on the product. One was located on the back of the product just above the storage pouch (see figure 2). It stated 'WARNING: NOT APPROVED FOR USE IN MOTOR VEHICLES'. This warning appeared in raised white letters against the product's white plastic shell (i.e., white-on-white format). The letter height was $3 / 16^{\prime \prime}$. The second warning appeared in the lower left-hand corner of the cardboard baby insert in black print on a light blue background. It stated: 'CAUTION: Not for use as a child car seat'. The letter height was $3 / 32$ ".

The product had holes in the side which were designed as handholds for carrying the product, but they might also suggest a location for a seat belt to pass through. Although the holes in the side of the product are too small for most automobile seat belt buckles, one of the seven car

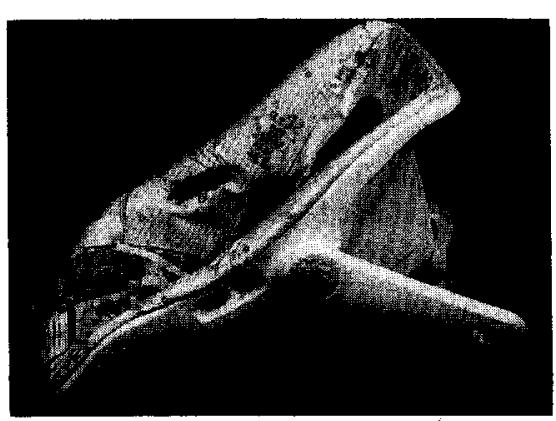

Condition 1 - Side view

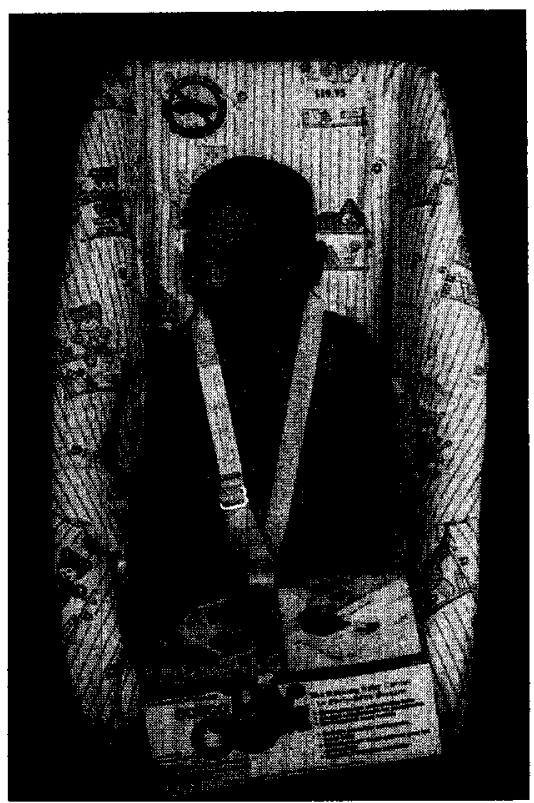

Condition 3 - Front view

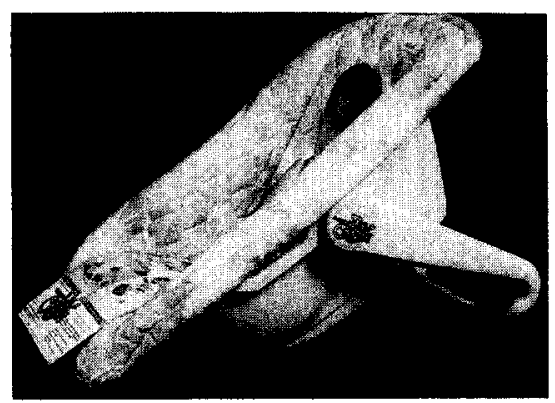

Condition 2 - Side view

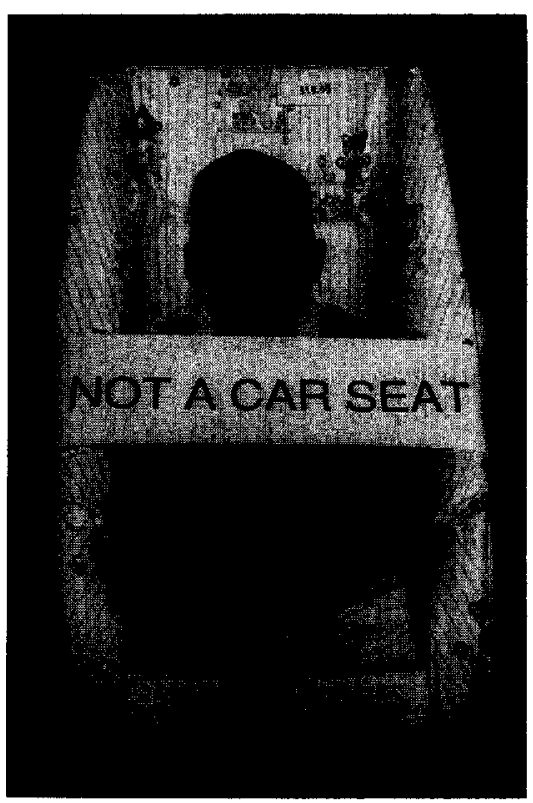

Condition 4 - Front view

Fig. 3. Infant carrier conditions. 


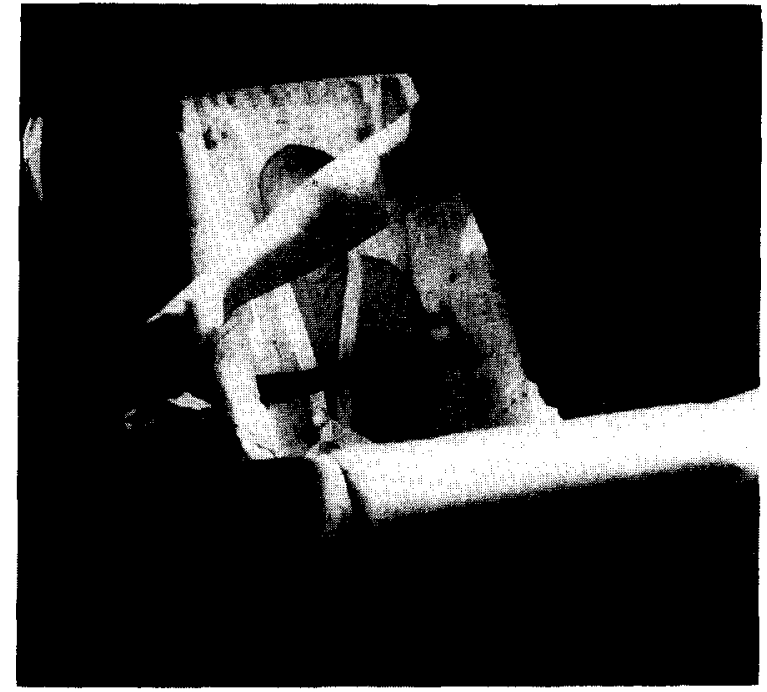

Fig. 4. Illustration of potential seat belt insertion affordance.

models we tested allowed for the seat belt to pass through the holes (see figure 4).

Given the characteristics of the warnings and the potential affordance for placing a seat belt through the handholds, this control condition was considered to have low warning salience and high affordance for use as a car seat relative to the other conditions.

Condition 2: Reduced affordance for use as car seat. This condition differed from the control condition in that a different model of the same infant carrier was used. In this condition, the product had a cloth lining that completely covered the holes in the side of the product, thus removing the appearance of a seat belt insertion point. The warnings were the same as in the control condition.

This condition was included to test the hypothesis that removing a design feature that might suggest an inappropriate use of the product would significantly increase the proportion of subjects recognizing the limitations of the product. More concretely, it was hypothesized that covering the holes in the side of the product would increase the proportion of subjects who recognized that the product was not designed for use as a car seat.

Condition 3: Moderate warning salience. This condition differed from the control condition in that the number and salience of the warnings was increased. The control condition warnings were modified in the following ways:

(1) The raised letters on the back of the product, 'WARNING: NOT APPROVED FOR USE IN MOTOR VEHICLES' were modified to appear in a red-on-white format instead of the initial white-on-white format.

(2) A professionally prepared label was added to the left shoulder strap (see figure 5). The label was printed in $1 / 8^{\prime \prime}$ high red letters on a white background and presented the same verbiage as that used by a competitor's infant carrier:

\section{WARNING: DO NOT USE AS CAR SEAT NEVER LEAVE BABY UNATTENDED. ALWAYS USE RESTRAINT DEVICE. DO NOT SET WITH BABY ON TABLETOP OR COUNTER.}

(3) A 2-1/4" diameter, circular warning symbol sticker was affixed to the upper left-hand corner on the front of the product (see figure 6). The sticker displayed a symbol of a blue car surrounded by the commonly used red

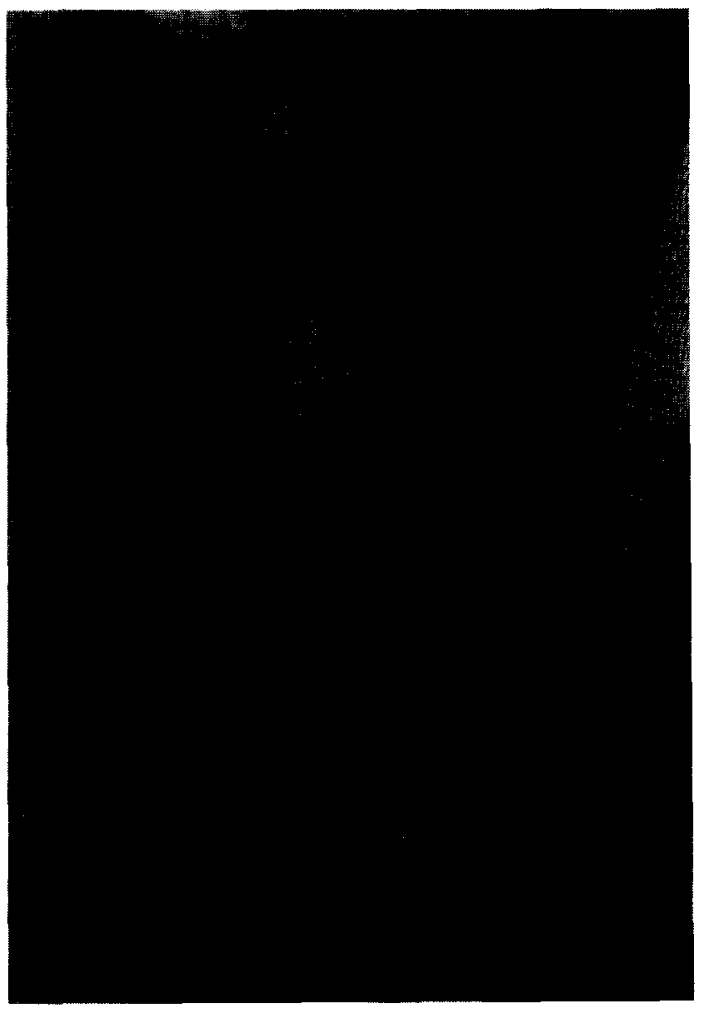

Fig. 5. Warning label added to shoulder strap in Condition 3. 
circle with a slash through it. Around the circumference of the circle were the words: 'DO NOT USE AS A CAR SEAT!' This sticker was also the same as that of a competitor's infant carrier.

The features of the product were the same as in the control condition (i.e., the holes in the side of the product were exposed).

Condition 3 was included to test the hypothesis that increasing the salience of warnings against the use of the product as a car seat would increase the proportion of subjects who would recognize that the product was not suitable for use in a car. Note that, relative to other carriers on the market, this condition represents a high level of on-product warning salience since the product warnings were a compilation of competitor products' warnings.

Condition 4: High warning salience. This condition was the same as the control condition except that a 4-inch wide, white banner was placed across the front of the product which stated in 1-1/8" high red letters, 'NOT A CAR SEAT'. A by-product of such a large banner was that it somewhat obscured the holes in the sides of the product.
This condition was included to test the hypothesis that increasing warning conspicuity beyond that of the typical infant carrier would result in the highest proportion of subjects attending to the message and recognizing the product was not suitable for use as a car seat.

\section{Results}

Table 1 shows the percentage of subjects in each condition who agreed with each of the key statements. The results shown in this table illustrate that, collectively, the features of the product prompted a large proportion of the subjects to incorrectly assess the safety-critical limitations of the product. In fact, by combining the responses to Conditions 1,2 , and 3 , in which the warnings were either of low or moderate salience, almost half of the subjects $(47 \%)$ incorrectly agreed that the product was designed to protect a baby in the event of an accident.

Planned comparisons between the control condition and each of the other conditions were conducted using chi-square tests. Since the results of chi-square tests were the same for re-

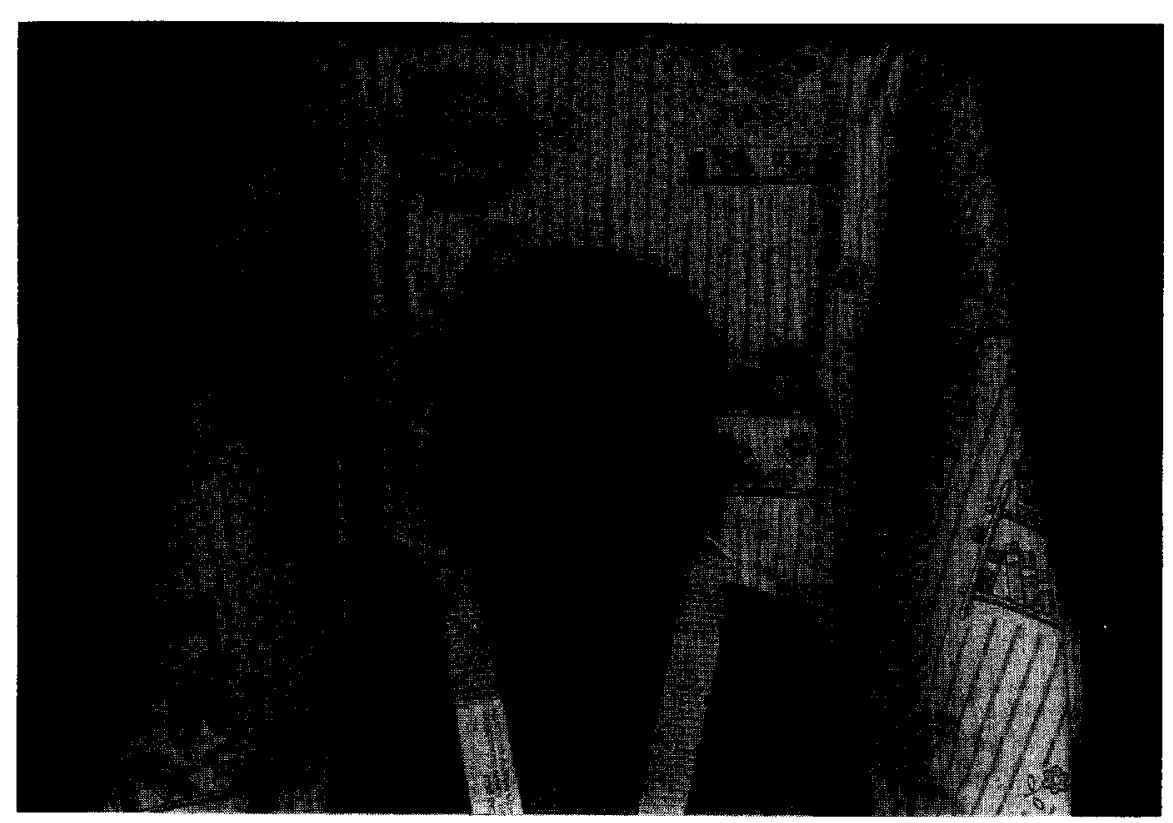

Fig. 6. Warning sticker added to upper left-hand corner in Condition 3. 
Table 1

Percentage of subjects agreeing with the following statements.

\begin{tabular}{|c|c|c|c|c|}
\hline & \multicolumn{4}{|l|}{ Condition } \\
\hline & $\begin{array}{l}1 \\
\text { Control } \\
\text { (Low warning salience/ } \\
\text { High affordance) } \\
(n=15)\end{array}$ & $\begin{array}{l}2 \\
\text { Reduced } \\
\text { car seat } \\
\text { affordance } \\
(n=15)\end{array}$ & $\begin{array}{l}3 \\
\text { Moderate } \\
\text { warning } \\
\text { salience } \\
(n=15)\end{array}$ & $\begin{array}{l}4 \\
\text { High } \\
\text { warning } \\
\text { salience } \\
(n=17)\end{array}$ \\
\hline $\begin{array}{l}\text { This product is designed for holding } \\
\text { a baby while it is riding in a car. }\end{array}$ & $67 \%$ & $60 \%$ & $47 \%$ & $12 \%$ \\
\hline $\begin{array}{l}\text { This product is designed to protect } \\
\text { a baby in the event of a car accident. }\end{array}$ & $60 \%$ & $40 \%$ & $40 \%$ & $6 \%$ \\
\hline
\end{tabular}

sponses to both key statements, only the results for the statement 'this product is designed to protect a baby in the event of a car accident' are presented.

Regarding the effect of visible holes in the side of the product, the proportion of subjects in Condition 1 did not differ significantly from Condition $2\left(\chi^{2}=1.2, N=30, p>0.10\right)$. As such, covering the holes in the side of the product did not significantly decrease the proportion of subjects who thought the product was designed to protect a baby in the event of an auto accident. However, three subjects who incorrectly thought that the infant carrier was designed to protect an infant in the event of an auto accident specifically mentioned that they thought the hand holes were for inserting a seat belt. Two other subjects who correctly recognized the limitations of the product noted that the hand holes might suggest to other people a place to insert a seat belt. In summary, covering the holes did not result in a statistically significant reduction in the number of subjects who incorrectly assessed the limitations of the product, but the presence of the holes did affect the judgments made by at least three subjects and perhaps more subjects who did not verbalize their perception of the holes in the side of the product.

With regard to the effect of warning salience on the correct perception of the infant carrier, the difference between Conditions 1 and 3 was not significant $\left(\chi^{2}=1.2, N=30, p>0.10\right)$, indicating that adding the competitor product warnings did not yield a significant reduction in the number of subjects who misperceived the intended use of the product. However, the difference between Conditions 1 and 4 was significant $\left(\chi^{2}=10.9, N=32, p<0.01\right)$ and the difference between Conditions 3 and 4 was significant $\left(\chi^{2}=\right.$ $5.4, N=32, p<0.05$ ). Thus, increasing the warning salience did not increase the proportion of subjects who correctly recognized the critical lim-

Table 2

Percentage of subjects who noticed and read any warnings on the product.

\begin{tabular}{|c|c|c|c|c|}
\hline & \multicolumn{4}{|l|}{ Condition } \\
\hline & $\begin{array}{l}1 \\
\text { Control } \\
\text { (Low warning salience/ } \\
\text { High affordance) } \\
(n=15)\end{array}$ & $\begin{array}{l}2 \\
\text { Reduced } \\
\text { car seat } \\
\text { affordance } \\
(n=15)\end{array}$ & $\begin{array}{l}3 \\
\text { Moderate } \\
\text { warning } \\
\text { salience } \\
(n=15)\end{array}$ & $\begin{array}{l}4 \\
\text { High } \\
\text { warning } \\
\text { salience } \\
(n=17)\end{array}$ \\
\hline $\begin{array}{l}\text { Percentage of subjects who noticed } \\
\text { any warnings on the product. }\end{array}$ & $13 \%$ & $13 \%$ & $67 \%$ & $82 \%$ \\
\hline $\begin{array}{l}\text { Percentage of subjects who read } \\
\text { any warnings on the product. }\end{array}$ & $7 \%$ & $7 \%$ & $53 \%$ & $82 \%$ \\
\hline
\end{tabular}


itations of the product, except in the most salient warning condition where the prominence of the on-product warning was well beyond that displayed by most, if not all, infant carriers.

Table 2 illustrates the percentage of subjects in each condition who noticed any of the warnings on the product and the percentage of subjects who read any of the warnings. With regard to the proportion of subjects who noticed any of the warnings in Conditions 1,3 , and 4 , chi-square tests found the difference between Conditions 1 and 3 to be significant $\left(\chi^{2}=8.9, N=30, p<0.01\right)$ as well as the difference between Conditions 1 and $4\left(\chi^{2}=15.2, N=32, p<0.01\right)$. However, the difference between Conditions 3 and 4 was not significant $\left(\chi^{2}=1.0, N=32, p>0.1\right)$. With regard to the proportion of subjects who read any of the warnings, Condition 4 resulted in a significantly higher proportion than Conditions 1 or 3 $\left(\chi^{2}=3.1, N=32, p<0.1\right.$ and $\chi^{2}=18.3, N=32$, $p<0.01$, respectively) and Condition 3 resulted in a significantly higher proportion than Condition $1\left(\chi^{2}=7.8, N=30, p<0.01\right)$. Thus, increasing the salience of the warnings significantly and substantially increased the proportion of subjects who attended to and read at least one of the warnings against using the product as a car seat.

Although warning comprehensibility was not specifically addressed in this study, it should be noted that all of the subjects who stated that they read at least one of the warnings correctly recognized that the product was not designed to protect a baby in an auto accident. This finding has implications for the assessment of the effectiveness of the moderate warning salience condition. Specifically, compared to the control condition there was a significant increase in the proportion of subjects who read the warning in Condition 3 (see table 1), but there was not a significant reduction in the proportion of subjects who thought the product was designed to protect an infant in the event of an automobile accident (see table 2). Based on this observation, one is tempted to conclude that the warning was read but had no effect on subjects' recognition of the product's limitation. Such a conclusion, however, would be incorrect since all eight subjects who noticed and read a warning on the product in this condition correctly recognized that the product was not designed to protect an infant in an automobile accident. The reason for this apparent contradiction in the results is that six of the seven subjects $(86 \%)$ in Condition 3 who did not read any of the warnings incorrectly thought that the product was designed for use in a car. The implication of this observation is that, with a larger sample size, increasing the level of warning salience to the 'moderate' level would probably yield a significantly lower proportion of incorrect subjects than the control condition. Certainly, from a practical standpoint, Condition 3 would be preferable to Condition 1.

With regard to the attention to particular warnings on the infant carrier, 5 of the 62 subjects $(8 \%)$ noticed the warning in raised letters on the back of the product and only 3 of them $(5 \%)$ actually read it. Only 2 of the 62 subjects (3\%) noticed and read the CAUTION statement on the point-of-purchase cardboard baby insert, despite the fact that many of the subjects spent considerable time looking at the promotional information on the cardboard insert. In Condition 3 , where a warning was added to the shoulder strap and a sticker was added to the upper lefthand corner of the product, none of the fifteen subjects noticed the warning on the shoulder strap and ten out of fifteen subjects $(67 \%)$ noticed the warning sticker, however, only eight of the ten actually read it. Finally, in Condition 4, where a large white banner was placed across the front of the product, 14 out of 17 subjects ( $82 \%$ ) noticed and read the statement on the banner.

With respect to demographic considerations, chi-square tests found that gender, age, and previous use of an infant car seat were not significantly related to experimental condition ( $p>0.50$ for all three factors). Thus, the relationship between these subject attributes and knowledge of product limitations could be assessed by pooling responses across all four conditions. Gender and previous use of an infant car seat were not significantly related to subject responses regarding the limitations of the product $(p>0.10)$. However, age was related to knowledge of product limitations $\left(x^{2}=7.7, N=62, p<0.01\right)$. More specifically, across the four conditions, $60 \%$ of the subjects 40 years and older incorrectly thought that the infant carrier was designed to protect an infant in the event of an automobile accident, while only $35 \%$ of the subjects under 40 had this 
misconception. A potential explanation for this difference was provided by a middle-aged man who remarked that the current infant carriers are noticeably larger and sturdier than the infant carriers of 20 years ago.

\section{Discussion and recommendations}

\section{Product features}

Since one of the key features of a car seat is a place to insert or attach a seat belt, it is somewhat surprising that covering the holes in the side of the product did not significantly reduce the confusion regarding the limitations of this product. Subject comments during and after the interviews suggested several reasons for this finding: (1) during the session subjects may not have been thinking about how they would actually use the product in their car, (2) subjects may have realized immediately that the holes in the side of the product were not large enough to permit their seat belt buckle to pass through and therefore, dismissed the holes as seat belt anchoring points, and (3) subjects may have assumed that the product would be secured by some means other than the seat belt passing through the hand holes.

Although the presence of the holes did not significantly affect subject perceptions on the whole, there were several individuals who thought the holes were meant for a seat belt to pass through. These individual misperceptions suggest that, for a small proportion of consumers, the holes in the side of the product present a product safety concern because they may prompt or facilitate inadvertent misuse of the product as a car seat. One possible solution to this problem would be to replace the holes with a closed, rounded ledge that still affords lifting, but eliminates the possibility of seat belt insertion. This solution stems from our more generic product safety recommendation which is: Design products with features that afford and suggest intended uses of the product, but do not prompt or facilitate unintended and potentially unsafe uses. Like verbal instructions and warnings, it is desirable that product features send unambiguous messages to product users.

Beside the hand hole feature, the combination of product features resulted in a surprisingly high proportion of subjects incorrectly assessing the intended use of the product. This finding suggests that evaluations such as this aimed at determining potential users' perceptions of intended and unintended uses of products are valuable in discovering and correcting product safety problems. In addition, such evaluations are useful in developing product safety information such as warnings, instructions, and point-of-purchase packaging (cf. Miller, Frantz and Rhoades, 1991). From a product safety standpoint, there is a pressing need to develop methodologies for identifying product affordances (both perceived and actual), in the pre-market stages of product development, that may prompt or facilitate unsafe uses of a product.

\section{Product warnings}

Regarding the effect of increasing the conspicuity of the warning, the results of this study call into question some common assumptions about the ability of certain warning features to attract attention. Specifically, the presence of a bright contrasting color on the back of the infant carrier, as opposed to the white-on-white format, did not increase the proportion of subjects who noticed the warning on the back of the product. In fact, only 1 out of 15 subjects noticed the red-on-white version. This finding is contrary to commonly held beliefs regarding the effect of contrasting colors and contrary to the opinion expressed by many of the subjects exposed to the white-on-white warning (i.e., the warning would be more noticeable if it were presented in a contrasting color). Note that the subjects' assessment of warning adequacy is quite similar to that typically asked of jurors in failure-to-warn litigation where no human factors expertise is available and/or no specific testing or research has been conducted to determine the effectiveness of the warnings in question. This finding is certainly counter to Hardie's (1991) position that jurors are completely capable of determining the adequacy of warnings unaided by human factors engineers with specialized training and expertise in the design and evaluation of warnings.

Also evidenced by this study was the difficulty in getting people to process verbal or graphic 
product information when their attention is directed toward other types of information. Specifically, 3 out of 17 subjects did not read the warning banner in Condition 4, and 5 out of 15 subjects did not notice the warning symbol on the front of the product in Condition 3. Note that, in this study, those subjects who already had relevant criteria by which to judge the products did not need to process verbal or graphic information, but only to examine the physical features of the product. The infant carrier, like many other products and environments, presents the warning designer with the challenge of attracting the attention of individuals who are not planning on processing verbal or graphic information during their interaction with the product or environment. A methodology for dealing with this challenge and improving the effectiveness of warnings in such situations was successfully applied by Frantz and Rhoades (in press). Using a task analytic approach, they systematically examined the cognitive and behavioral elements of a particular task and used the analysis to identify temporal and spatial warning locations that effectively integrated or inserted the warning stimulus into the user's flow of information processing. With more knowledge of the behavior of individuals who are actually shopping for infant carrier products, this task analytic methodology could also be used to develop alternative warnings for infant carriers.

In closing, the nonintuitive nature of our findings regarding warning salience provides additional evidence that proposed warning solutions need to be evaluated in some manner beyond subjective impressions as to how they will perform. The importance of warning evaluation has been stressed by a number of authors (cf. Cunitz, 1981; Laughery and Brelsford, 1991; Miller, Frantz, and Rhoades, 1991; Robinson, 1986). Just as it is important to evaluate the physical design of a product along such dimensions as strength, reliability, and durability, it is important to evaluate proposed warnings along relevant dimensions such as attractiveness, comprehensibility, memorability, and behavioral effectiveness. Unfortunately, systematic evaluations of product warnings and instructions are not typically conducted (Moore, 1991). Our recommendation and hope is that research efforts continue not only in the general area of warning design, but also in the more specific area of warning evaluation methodologies so that systematic evaluations of warnings are more readily available and more widely conducted.

\section{Acknowledgements}

The authors extend thanks to Bruce Main and Candida Iqball for their assistance in planning and conducting this research.

\section{References}

Baggett, P. and Ehrenfeucht, A., 1988. Conceptualizing in assembly tasks. Human Factors, 30(3): 269-284.

Cunitz, R.J., 1981. Psychologically effective warnings. Hazard Prevention, 17(3): 12-14.

Frantz, J.P. and Rhoades, T.P., in press. A task analytic approach to the temporal and spatial placement of product warnings. Human Factors.

Gibson, J.J., 1977. The theory of affordances. In: R. Shaw and J. Bransford (Eds.), Perceiving, Acting, and Knowing: Toward an Ecological Psychology. John Wiley and Sons, New York.

Gillis, J. and Fice, M.E.R., 1986. The childwise catalog: A consumer guide to buying the safest and best products for your children - newborns through age five. Pocket Books: New York.

Hardie, W.H., 1991. Can experts evaluate the effectiveness of warnings? For the Defense, 10: 14-21.

Jones, S., 1988. Guide to baby products. Consumers Union, Mount Vernon.

Laughery, K.R. and Brelsford, J.W., 1991. Receiver characteristics in safety communications. In: Proceedings of the Human Factors Society 35 th Annual Meeting, Santa Monica.

MacGregor, D.G., 1989. Inferences about product risks: A mental modeling approach to evaluating warnings. Journal of Products Liability, 12(1): 75-91.

Miller, J.M., Frantz, J.P. and Rhoades, T.P., 1991. A model for developing and evaluating product information. In: Proceedings of the Human Factors Society 35th Annual Meeting, Santa Monica.

Moore, M.G., 1991. Product warning effectiveness: Perception vs. reality. Professional Safety, 4: 21-24.

National Child Passenger Safety Association, 1985. Special edition: Product Update 1985. Child Passenger Protection Report 2(3): 1.

Norman, D.A., 1988. The psychology of everyday things. Basic Books, New York.

Rhoades, T.P., Frantz, J.P. and Miller, J.M., 1990. Emerging methodologies for the assessment of safety related product communications. In: Proceedings of the Human Factors Society 34th Annual Meeting, Santa Monica. 
Rhoades, T.P. and Miller, J.P., 1992. Methods used on atypical climbing systems. In: S. Kumar (Ed.), Advances in Industrial Ergonomics and Safety IV. Taylor and Francis, London, pp. 1021-1028.

Robinson, G.H., 1986, Towards a methodology for the design of warnings. In: Proceedings of the Human Factors Society 30th Annual Meeting, Santa Monica.

U.S. Department of Transportation, 1981. Federal Motor Vehicle Safety Standard 213, Child restraint systems. 49 CFR 571.213. 